\title{
The "Polluter Pays Principle": Should Liability be Extended When the Polluter Cannot Pay?
}

\author{
by James Boyd and Daniel E. Ingberman*
}

\section{Introduction}

When pollution causes a social loss, who should be liable? Common sense, standard legal doctrine, and notions of economic efficiency agree that liabilities should in general be assigned to the polluters; that is, the polluter should pay. When the polluter's wealth is insufficient to pay all damages, however, liability is often extended beyond the direct polluters to more passive parties who merely contract or transact with the polluter. The underlying motivation for extending liability is cost internalization: extending liability expands the capital available to compensate victims and, by forcing greater joint cost internalization and monitoring, can be expected to induce more efficient safety investments. As an example of this view, Hansmann and Kraakman (1991) have argued that there should be unlimited shareholder liability for corporate torts. And Skogh (1991) identifies the beneficial role that financial intermediaries can play in monitoring and signalling the safety or quality of firms they guarantee. The rationale has also been put forward in the literature on vicarious liability (the liability of principles for the actions of their agents), as in Sykes (1984) and Kornhauser (1982). ${ }^{1}$

Is the logical conclusion, then, that liability should always be extended in order to maximize the internalization of liabilities and promote optimal risk reduction? We show that the answer is no. The prospect of being liable for the actions of another can affect the organization and performance of markets. Extended liability can reduce efficiency if, for instance,

* Boyd is a Research Fellow at Resources for the Future. 1616 P St. NW. Washington, DC 20036. Ingberman is Associate Professor at the John M. Olin School of Business, Washington University. St. Louis, Missouri 63130-4899. For their comments, we thank Nick Dopuch, Phil Dybvig, Ron King, Göran Skogh, the anonymous referees, and seminar participants at Washington University, the 1994 American Law and Economics Association meetings, and the 1995 joint meetings of the Geneva Association and the European Association of Law and Economics.

${ }^{1}$ Like Skogh, but in contrast to the literature on vicarious liability, our analysis features riskneutral contracting parties. 
it hinders transactions that yield scale economies. Thus, a tradeoff can arise. Extended liability promotes greater joint cost internalization and safety, but may distort transactions and raise overall production costs.

To explore these tradeoffs we develop a model with polluters - who directly control a risk - and contractors, who cannot control the risk, but require the polluter's product as an input to their own profit-maximizing activities. The model has the following general features. First, the extension of liability to contractors is triggered by a polluter's inability to internalize its liability due to insolvency. Second, polluters' safety and capital choices are endogenously derived. Third, transactions between polluters and contractors are allowed to emerge endogenously, as a function of the liability rule.

Three liability rules are considered: (1) polluter-only liability, in which liability is never extended to contractors, (2) proportional liability, in which liability is extended to contractors but limited to their proportional shares of the polluter's residual liability, and (3) joint and several liability, in which deeper-pocketed contractors can be liable for costs not internalized by shallower-pocketed contractors.

The endogeneity of capital investments and transactions plays a central role in the analysis. A polluter's capital investment defines the scale of liabilities extended to contractors and serves as a signal to contractors of the polluter's safety incentives. The endogeneity of the terms of, and decision to participate in, a transaction with a liability-generating trading partner is an issue that existing studies of extended liability have ignored. Kornhauser and Revesz (1990) and Tietenberg (1989), for instance, consider models where multiple defendants jointly dispose of pollution. Significantly, however, these authors assume that the firms cannot refuse to be contractually associated with their subsequent co-defendants or condition contracts on their solvencies or levels of safety. Since the pattern of transactions will reflect potential tradeoffs between safety and productive efficiency, it is important that these be endogenously determined in the model. Similarly, although the distortions in capital choice implied by liability have been discussed by previous authors, this is the first paper to model firms' choice of capital in a liability context involving multiple potential defendants. Notably, Ringleb and Wiggins (1990) and Wiggins and Ringleb (1992) have viewed solvency as a firm choice that is sensitive to liability. They have not, however, addressed the issues raised when joint liability is incurred by participating in a transaction.

The analysis proceeds in the following manner. Section 2 defines the model. Section 3 establishes an important benchmark: capital and safety choices under the polluter-only liability rule. Although polluter-only liability can lead to the first-best, under intuitive conditions it leads to suboptimal capital and safety choices. Under a polluter-only liability rule, contractors - bearing no risk themselves - are indifferent to the polluter's safety and solvency. Section 4 compares the polluter-only rule to extended liability. When liability is extended, contractors - since they expect to bear at least a fraction of risks that would otherwise be externalized to victims if the polluter is made insolvent by damages - benefit from increased polluter safety and capital investments. As a result, contractors' demand for a polluter's product depends, not only on prices, but also on the expected liability implied by a contractual relationship with the polluter. In general, extended liability increases polluters' incentives to invest in capital and safety. However, extended liability can create productive inefficiencies due to lost scale or scope economies. This tradeoff can reduce the desirability of extended liability. In particular, these potential distortions imply that proportional liability can lead to greater welfare than joint and several. 


\section{The model}

Markets are composed of polluters and contractors. Polluters provide a product or service that is a necessary input to contractors' profit-maximizing activities. As a by-product of their production, polluters generate risks which can be reduced through their investments in safety. Contractors, however, have no direct control over risk. Absent an assignment of liability, the risks created by polluters impose costs on third parties. Thus, consumers who transact with contractors do not condition their demand on risk that may be externalized by polluters or contractors.

\subsection{Liability rules}

We contrast two types of liability rules, polluter-only liability and extended liability. Under the polluter-only rule, the polluter alone is liable even if, due to bankruptcy, it is unable to pay all damages. In the event of bankruptcy, the residual damages - the difference between assessed damages and the polluter's aggregate capital value - are externalized to third parties.

In contrast, extended liability assigns liability for residual damages to the contractors who transacted with the polluter. Damages are imposed on contractors only after the polluter is left insolvent. In that case, residual damages are initially assigned to all contractors with whom the polluter has contracted on a proportional basis. For instance, if the polluter makes $q$ units that are sold to $q$ contractors, each contractor's initial liability equals $(1 / q)^{\text {th }}$ of the residual damages. In the event that some contractors are made insolvent by this initial proportional allocation of residual damages, however, we consider two types of extended liability: joint and several and proportional. Under proportional liability, contractors' liabilities are limited to their proportional share of the residual damages; if this bankrupts some contractors, any remaining residual damages are externalized. By contrast, under joint and several liability, each contractor can be held liable for the full amount of the residual damages. Thus, if the initial proportional assignment of residual damages leaves some contractors insolvent, then the remaining solvent contractors are proportionally liable for the remaining damages not borne by other insolvent contractors.

\subsection{Capital choice, information, and the timing of decisions}

The timing of decisions is as follows. First, each polluter invests in productive (equity) capital that is immobile until all liabilities are realized and satisfied. ${ }^{2}$ Second, the polluter chooses its output and safety. ${ }^{3}$ Third, contractors and polluters transact in a perfectly competitive market. Fourth, product risks are realized as actual damages, and costlessly adjudicated according the liability rule in place.

2 Throughout this paper, we treat capital as equity capital. Alternatively, one can derive the same result by assuming that the firm has a choice between financing through equity or debt capital since, if tort liabilities have priority over debt in bankruptcy, the firm will strictly prefer equity financing. This follows because the priority of liabilities over debt payments increases the cost of debt financing. On the other hand, if debt has priority over torts, then our analysis may understate the likelihood that punitive damages will reduce deterrence. For an analysis of some of the issues that arise when secured credit has priority over torts, see Ingberman (1994).

3 Our results are unaffected by the alternative assumption that capital, safety, and output are chosen simultaneously. The timing we have specified and the notational dependence of $\hat{s}(\cdot)$ and $\hat{\mathrm{q}}(\cdot)$ on $k$ simplifies the intuition behind the model and emphasizes the role of capital as a signal of polluters' subgame perfect safety choices. 
All markets are competitive. This means that capital investments earn an expected rate of return equal to the economy-wide (opportunity) cost of capital. Competition also implies that the total (private) surplus to polluters and contractors is maximized in equilibrium. As a result, under polluter-only liability rule, the polluter's capital intensity, safety, and output choices minimize the representative polluter's (expected) average cost. However, when liability is extended, contractors are residually liable and therefore discount their demand on the basis of a polluter's capital and inferred safety investments. In this case, equilibrium polluter choices maximize joint polluter-contractor surplus, given the contractors' residual liability.

Polluters pick from a set of production technologies, each of which is characterized by a distinct capital intensity. For a given technology, let

$$
k=\text { the capital intensity associated with that technology. }
$$

Specifically, $k$ measures the amount of legally recoverable capital needed to produce a unit of output with that technology. Assume $k$ does not vary with output. Thus, $k$ indexes the polluter's choice of technology as well as the amount of equity capital that is available to compensate victims. Choosing a technology with greater capital intensity benefits the polluter by reducing production costs and, when liability is extended, by signaling greater safety investments to potential contractors. All else equal, however, higher $k$ 's increase direct capital costs, the polluter's expected liability, and its implied safety costs.

The polluter's optimal output and safety choices are a function of $k$. Specifically, define

$$
\begin{aligned}
\{\hat{\mathrm{q}}(k) \hat{\mathrm{s}}(k)\}= & \text { the polluter's private, cost-minimizing output and safety } \\
& \text { choices, given a production technology with capital intensity } k .
\end{aligned}
$$

We assume that safety cannot be directly observed by contractors. However, contractors can directly observe polluter capital choices. Importantly, because a polluter's capital intensity defines the degree to which it internalizes costs, contractors can infer a polluter's private cost minimizing safety investment and output choice through observation of $k$. Indeed, the polluter's choice of $k$ will be optimal in the sense that it maximizes total (private) surplus between the polluter and the contractors with which it transacts. The only limitation we impose here is that the polluter makes a single choice of $k$, which is the same for every transaction it engages in.

\subsection{Production and risk reduction}

A polluter's total costs are the sum of its direct production costs, expenditures on safety, and expected liabilities. Let

$\mathrm{C}(q, k)=$ the polluter's total direct production cost, given $k$ and $q$, and

$\mathrm{L}(q, k, s)=$ the polluter's total expected liabilities, given $k, q$, and $s$.

Thus, for any $k, s$, and $q$, the polluter's average cost is

$$
\mathrm{AC}=\frac{s+\mathrm{C}(k, q)+\mathrm{L}(q, s, k)}{q}
$$

We now more fully specify $\mathrm{C}(q, k)$ and $\mathrm{L}(q, k, s)$. 
Expected liability. First consider the polluter's expected liability $\mathrm{L}(q, k, s)$. Under both polluter-only and the extended forms of liability, the polluter is required to satisfy all liability claims up to its capital value. Thus, all else fixed, the polluter's expected liability is the same under both types of rule. Assume that any unit of the firm's output can fail, and each unit of product failure creates a social cost L. Let $b$ denote the fraction of the polluter's output that fails. For any value of $b$ between 0 and 1 , let $r(b, s)$ denote the probability that a fraction $b$ fails, given the polluter's safety expenditure, $s .^{4}$

Assume that damages are compensatory, so the polluter is never assessed damages that exceed $q \mathrm{~L}$. Moreover, liability is limited, so the polluter cannot be held liable for damages that exceed its total capital value $k q$. We will say that a polluter is fully capitalized when $k \geq \mathrm{L}$, and undercapitalized when $k<\mathrm{L}$. Fully capitalized polluters have sufficient capital value to internalize the largest possible damages that can be assessed $(b=1)$. Undercapitalized polluters - since some realizations of product failure leave them insolvent $(b \geq k / \mathrm{L})-$ do not bear the full expected costs of product failure. Thus, for any $q$ and $s$, an undercapitalized polluter's total expected liabilities are given by

$$
\mathrm{L}(q, k, s)=\left[\mathrm{L} \int_{0}^{k / \mathrm{L}} b \cdot r(b, s) d b+k \int_{k / \mathrm{L}}^{1} r(b, s) d b\right] \cdot q
$$

The bracketed expression in (2) is the expected liability of the firm per unit of output. To interpret this expression, note that when the fraction of failed output $b$ is less than $k / \mathrm{L}$, the undercapitalized polluter remains solvent. If so, the polluter bears the full value of the damages it is assessed. This yields the first integral in (2). However, realizations $b$ that exceed $k / \mathrm{L}$ bankrupt the polluter. These outcomes are reflected in the second integral in (2). ${ }^{5}$

Production costs. Given an initial choice of capital intensity $k$, the polluter's direct production cost can be written as

$$
\mathrm{C}(k, q)=\mathrm{c}(k, q)+q w k
$$

where $w$ is the direct (opportunity) cost of capital and $\mathrm{c}(\cdot)$ is decreasing (at a decreasing rate) in $k$ and increasing (at an increasing rate) in $q$. Given the specification of $\mathrm{C}(q, k)$ and

\footnotetext{
${ }^{4}$ As will be clear, it is important to permit a continuous range of loss outcomes in order to fully capture the effects of extended liability. The more commonly employed "two-point" distribution over loss (where the polluter generates a loss L with probability $p(s)$, and no loss with probability 1- $p(s)$ ) is a special case of our formulation. However, the possibility of losses of intermediate scale is important in this model since it is in such cases that extended liability will lead to the insolvency of some contractors but not others. Thus, when any fraction of loss $b$ between zero and one is possible, joint and several liability implies the subsidization of shallower-pocketed contractors' liability by deeper-pocketed contractors. The two-point distribution cannot capture this type of outcome.
}

${ }^{5}$ Observe that if $k \geq \mathrm{L}$, then the firm is solvent for every possible realization of product failure. In that case, replace " $k / L "$ with " 1 " in equation (2). 
$\mathrm{L}(q, k, s)$ average costs are U-shaped in $q$. Returns to scale are indexed by the level of output which minimizes average costs. Large scale economies are associated with markets in which the costs $\mathrm{C}(k, q)+s$ are minimized at a large $q$, relative to the size of the market.

\section{Polluter-only liability and the first best}

This section characterizes a polluter's capital and safety investments under the polluteronly rule. In contrast to most models of liability and potential insolvency, we derive the firm's capital choice endogenously. The endogenous derivation of capital choice is central to the analysis since a polluter's insolvency triggers the extension of liability. Let

$$
\begin{aligned}
\mathrm{k}^{*}= & \text { the first-best (social welfare maximizing) capital intensity for the polluter, } \\
& \text { or the } k \text { which equates the marginal productive benefits of capital to } \mathrm{w} ; \\
\mathrm{s}^{*}= & \text { the first-best safety expenditure; and } \\
\hat{\mathrm{k}}= & \text { the firm's choice of capital intensity under polluter-only liability. }
\end{aligned}
$$

Given these definitions, we have

PROPOSITION 1: Under the polluter-only liability rule, polluters make inefficiently low investments in capital and safety if potential liabilities exceed assets given the efficient capital investment (if $\mathrm{k}^{*}<\mathrm{L}$, then $\hat{\mathrm{k}}<\mathrm{k}^{*}$ and $\hat{\mathrm{s}}(\hat{\mathrm{k}})<\mathrm{s}^{*}$ ). Otherwise, the polluteronly rule induces first-best capital and safety decisions.

A formal proof of this result appears in the appendix. Here we focus on the intuition. First recall that $\hat{s}(k)$ denotes the polluter's equilibrium safety expenditure as a function of its initial choice of $k$. Comparative static techniques show that for $k<\mathrm{L}, \hat{\mathrm{s}}(k)$ increases with $k$. Once the polluter is fully capitalized $(k \geq \mathrm{L})$, then $\hat{\mathrm{s}}(k)=\mathrm{s}^{*}$.

Now consider the polluter's initial choice of $k$. Define

$$
\mathrm{AC}(k)=\mathrm{AC}(k, \hat{s}(k), \hat{\mathrm{q}}(k))=\min _{s, q} \mathrm{AC}(k, s, q) .
$$

$\mathrm{AC}(k)$ is simply $\mathrm{AC}(k, s, q)$ (equation (1)) with $\hat{\mathrm{s}}(k)$ and $\hat{\mathrm{q}}(k)$ replacing $s$ and $q$; that is, $\mathrm{AC}(k)$ is the value of average cost that results from capital intensity $k$ when $s$ and $q$ are chosen to minimize average costs, for the given value of $k$.

In market equilibrium, the polluter invests in the $\hat{k}$ which solves

$$
\min _{k} \mathrm{AC}(k) \text {. }
$$

The benefits of a technology with a higher $k$ are lower direct production costs. The tradeoff is that, all else equal, higher $k$ 's imply larger expected liabilities.

The benefits of greater capital intensity $k$ (i.e., reduced production costs) are concave in $k$. Therefore, the marginal benefits of $k$ are downward sloping. However, the marginal costs of capital are also downward sloping. In particular, the marginal cost of $k$ is

$$
w+\int_{k / \mathrm{L}}^{1} r(b, \hat{s}(k)) d b .
$$


That is, the marginal cost of capital is simply the sum of the opportunity cost of capital plus the probability of bankruptcy, given the equilibrium safety and output choices induced by a given value of $k .{ }^{6}$ As $k$ increases, the probability of bankruptcy from damages falls. Thus, the polluter's marginal cost of $k$ is downward sloping in $k$. But as $k$ approaches $\mathrm{L}$, the marginal cost of $k$ approaches the opportunity $\operatorname{cost} w$, since the probability of bankruptcy approaches zero.

Although downward sloping marginal costs raise the possibility of multiple equilibria, this complication does not affect the conclusions of our analysis. ${ }^{7}$ Therefore, we assume that $\hat{\mathrm{k}}$ is always uniquely defined by the first-order condition associated with problem(4). ${ }^{8}$

The polluter's marginal cost of $k$ strictly exceeds the social marginal cost for all $k$ 's that leave the polluter undercapitalized, i.e., whenever $k<\mathrm{L}$. Therefore, when $\mathrm{k}^{*}<\mathrm{L}$, the polluter never chooses the first-best capital intensity $\mathrm{k}^{*}$.

To conclude: Whenever the first-best capital choice leaves a polluter undercapitalized relative to the scale of its potential liabilities, the polluter-only liability rule leads the firm to underinvest in capital $\left(\hat{\mathrm{k}}<\mathrm{k}^{*}\right)$ and safety $\left(\hat{\mathrm{s}}<\mathrm{s}^{*}\right)$. In the next section, we investigate the ability of extended liability rules to overcome this inefficiency.

\section{Extended liability}

In this section, we first derive the effects of extended liability when all contractors are identically capitalized (have equal amounts of legally recoverable wealth). This provides a benchmark which highlights the benefits of internalizing greater liability costs with extended liability. When contractors are identically capitalized, extending liability affects only the polluter's choices, and not the pattern of polluter-contractor relationships. Therefore, the bulk of the analysis focuses on markets in which contractors are heterogeneous in their capitalization.

\footnotetext{
${ }^{6}$ For example, consider the special case of the two-point loss distribution; the intuition is similar to the marginal analysis of a continuous loss distribution. That is, suppose the firm has total capital value $\mathrm{K}$, a loss $\mathrm{L}>\mathrm{K}+1$ occurs with probability $p(s)$, and no loss occurs with probability $1-p(s)$. Imagine that the polluter is considering an increase in capitalization from $\mathrm{K}$ to $\mathrm{K}+1$. With probability $1-p$ the firm is solvent, and the marginal cost of increasing $\mathrm{K}$ one unit is simply the opportunity cost, $w$, since the incremental investment in capital will be retrieved by the polluter. However, with probability $p$ the firm is insolvent, and in that case the incremental increase in capital is lost. Thus, when the firm is insolvent, the marginal cost of increasing $\mathrm{K}$ by one unit is $1+w$. Therefore, the expected marginal cost of increasing $\mathrm{K}$ by one unit is $p \cdot(1+w)+(1-p) \cdot(w)=p+w=$ the marginal opportunity cost of capital plus the probability of bankruptcy.

${ }^{7}$ Given downward-sloping marginal costs, $\hat{\mathrm{k}}$ need not be unique: multiple technologies $k$ can in principle yield identical, minimized expected average costs. However, even with this non-convexity, under weak assumptions the first-order conditions of (4) are necessary to describe $\hat{k}$. Since the argument made to prove Proposition 1 only relies on first-order conditions, the possibility that $\hat{k}$ is not unique does not alter the result that $\mathrm{k}^{*}<\mathrm{L}$ implies $\hat{\mathrm{k}}<\mathrm{k}^{*}$.

8 This is always true when the marginal benefit of capital equals $+\infty$ at $k=0$ and marginal benefits always cut marginal costs from above. Under these conditions (since the marginal cost of capital at $k=0$ equals $1+w$ ), by continuity the first order condition associated with problem (4) is necessary and sufficient to describe $\hat{k}$.
} 


\subsection{Homogenous contractors}

Consider a set of contractors, each having the same amount of legally recoverable wealth or capital value, denoted $j>0$, and who each place equal value on the polluter's output as a necessary input to their own production processes. Each contractor requires one unit of a polluter's output. It is important to note that when contractors are identically capitalized, the proportional and joint and several rules yield equivalent expected contractor liabilities, and thus affect polluters' incentives identically.

When liability is extended, contractors condition their demands on their expected residual liability. While we do not permit contractors to condition their demands on polluter safety directly, they can condition on polluters' capital investments. Contractors know the polluter's subgame perfect safety investment $\hat{s}(k)$, given its capital intensity $k$. For the remainder of this subsection we restrict attention to the case where $\mathrm{k}^{*}<\mathrm{L}$, so that polluteronly liability leads to capital and safety investments that are strictly below the first-best. Recall that the scale of social loss is indexed by $b$, which ranges from 0 (no loss) to 1 (the maximum loss $q \mathrm{~L}$ ). Contractors bear liability costs whenever the scale of loss $b>K / \mathrm{L}$ (since in this case the polluter cannot fully satisfy the claims against it). If $b<(j+k) / \mathrm{L}$, then contractors fully internalize the residual liability. But if $b>(j+k) / \mathrm{L}$, both the polluter and contractors are left insolvent.

Let $\beta$ denote the gross benefits to a contractors of transacting with any polluter. Then the expected net benefits of the transaction of the contractors, as a function of the polluter's choice of $k$, are

$$
\mathrm{B}(k)=\beta-\int_{k / \mathrm{L}}^{\left(j_{i}+k\right) / \mathrm{L}}(\mathrm{L} b-k) \cdot r(b, \hat{s}(k)) d b+\int_{\left(j_{i}+k\right) / \mathrm{L}}^{1} j \cdot r(b, \hat{s}(k)) d b
$$

when $j+k<\mathrm{L}$, and

$$
\mathrm{B}(k)=\beta\left[\int_{k / \mathrm{L}}^{1}(\mathrm{~L} b-k) \cdot r(b, \hat{s}(k)) d b\right]
$$

when $j+k \geq \mathrm{L}$.

The equilibrium polluter capital intensity under extended liability maximizes the joint profits of polluters and contractors.

$\hat{\mathrm{k}}(j)=$ the equilibrium polluter $k$ under extended liability, given contractors' homogenous wealth levels, $j$.

That is, $\hat{k}(j)$ solves

$$
\max _{k} \mathrm{~B}(k)-\mathrm{AC}(k)
$$

Given homogenous contractors, the central effects of extending liability on capital and safety are as follows. (The appendix provides a more formal proof of these results.)

First, compared to polluter-only liability, polluters invest strictly more in both capital and safety under extended liability:

$$
\hat{\mathrm{k}}(j)>\hat{\mathrm{k}} \text {, and } \hat{\mathrm{s}}(\hat{\mathrm{k}})<\hat{\mathrm{s}}(\hat{\mathrm{k}}(j)) \text {. }
$$


To see why, observe that holding safety fixed, an increase in the polluter's $k$ transfers expected damages from the contractor to the polluter. However, increases in $k$ also signal increased safety. Greater $k$ imply greater cost internalization by the polluter, which implies a greater privately optimal investment $\hat{\mathbf{s}}(k)$. Increased safety is valued by contractors due to their liability exposure. An increase in $k$, then, is more than just a transfer of liability from the contractor to the polluter. It also implies an increase in joint surplus since higher $k$ 's induce the polluter to increase its safety expenditures. Given extended liability, the safety investment made under polluter-only liability is jointly sub-optimal. Increased capital intensity allows the polluter to credibly signal its safety incentives, and therefore increases contractors' willingness to pay by more than the incremental cost of capital.

Second, for values of contractor wealth $j$ such that

$$
\mathrm{L}-\hat{\mathrm{k}}(j)>j>0,
$$

the polluter's optimal capital investment $\hat{\mathrm{k}}(j)$ is increasing in contractor wealth $j$. This is intuitive since extended liability forces greater joint cost internalization than polluteronly liability. As $j$ increases over this range, contractors demand greater capital and safety investments. Contractors with wealths $j$ great enough to internalize all residual liability $(j \geq \mathrm{L}-\hat{\mathrm{k}}(j))$ demand identical polluter investments since they have identical residual liability exposures.

Third, we can characterize the relative efficiency of investments $\hat{\mathbf{k}}(j)$ and $\hat{\mathbf{s}}(\hat{\mathrm{k}}(j))$. Proposition 1 showed that polluter-only liability yields first-best polluter capital and safety investments when $\mathrm{k}^{*} \geq \mathrm{L}$. There is an analogous condition involving the combined capital values of the polluter and contractor which guarantees second-best investments when liability is extended. Define the second-best value of $k$ as

$\hat{\mathrm{k}}^{*}=$ the welfare-maximizing polluter capital intensity, subject to the constraint that the polluter makes the private cost minimizing safety investment $\hat{s}(k)$, given its capital intensity $k$.

When the first-best capital choice, $\mathrm{k}^{*}$, is strictly less than $\mathrm{L}$, we know that

$$
\hat{\mathbf{k}}<\mathrm{k}^{*}<\hat{\mathbf{k}}^{*} \leq \mathrm{L} .
$$

We also know that the safety investment implied by $\hat{k}^{*}, \hat{s}\left(\hat{k}^{*}\right)$, cannot exceed $s^{*}$. These results follow since the first-best capital intensity reflects only the productive benefits of capital, while the second-best also reflects the benefits of enhanced safety made credible by the polluter's greater capital intensity $\left(\mathrm{k}^{*}<\hat{\mathrm{k}}^{*}\right)$. The second-best capital investment cannot exceed $\mathrm{L}$, since $\mathrm{k}^{*}<\mathrm{L}$ and capital intensities greater than $\mathrm{L}$ do not induce the polluter to make safety investments greater than $\mathrm{s}^{*}$.

We will say that the polluter and contractor are jointly fully capitalized when

$$
\hat{\mathrm{k}}^{*}+j \geq \mathrm{L},
$$

i.e., when their combined capital value is sufficient to pay the damages resulting from any possible loss. When $\mathrm{k}^{*}<\mathrm{L}$, the second-best capital and safety investments arise only if (12) holds. Because contractors cannot condition their demands on polluters' safety choices directly, undercapitalized polluters will not make first-best safety choices. If, at the secondbest capital investment, the polluter and contractors are jointly fully capitalized, then the 
second-best capital investment must be an equilibrium (the joint surplus-maximizing solution to (8)) is $\mathbf{k}$ ). If (12) does not hold, then $\mathbf{k}(j)<\hat{\mathrm{k}}^{*}$. In this case the second-best cannot be an equilibrium, since at $k=\hat{\mathrm{k}}^{*}$, liabilities are not jointly internalized.

To conclude, extending liability to contractors leads them to demand greater polluter capital intensity as a signal of safety. As a result, relative to polluter-only liability, extended liability increases the efficiency of capital and safety investments, by making private marginal benefits and costs more closely mirror the social benefits and costs. As we demonstrate below, however, the optimality of extended liability need not hold when contractors are heterogeneous in their wealth.

\subsection{Heterogeneous contractor types and endogenous market structure}

When contractors have identical wealth, they have identical preferences over the "insurance" against residual liability implied by the polluter's investments $k$ and $\hat{\mathbf{s}}(k)$. It is perhaps most plausible that contractors are homogenous when they are in the same market. However, when a polluter transacts with contractors that sell in different markets, contractors are likely to have different levels of wealth. And when contractors differ in wealth they have incentives to transact with polluters dedicated to their own wealth-types. This follows for two reasons. First, as shown above, contractors with more wealth (higher $j$ 's) prefer more capital-intensive polluters (who bear relatively more liability, and thereby have greater incentives to invest in safety) than do contractors with less wealth. Second, when liability is joint and several, wealthier contractors expect to partially subsidize the proportional shares of liability of less wealthy contractors. Both forms of extended liability therefore can lead to a "separating" equilibrium, in which shallow-pocketed contractors transact with similarly shallowpocketed polluters and deep-pocketed contractors transact with deep-pocketed polluters.

When these incentives alter the equilibrium pattern of polluter-contractor transactions, extended liability can reduce welfare. In particular, when production exhibits scale economies, production efficiency is maximized by a "pooling" equilibrium in which heterogeneous contractors all transact with a common polluter. When contractors are heterogeneous, then, a tradeoff can arise when liability is extended. Extended liability can maximize the internalization of liabilities - and improve safety - but at a cost of reduced production efficiency. In this section we explore how this tradeoff depends on economies of scale, heterogeneous contractor wealth, and the form of extended liability.

\section{Market equilibrium with the proportional liability rule}

As before, assume that each contractor demands at most one unit of polluters' output. To illustrate our results, it is sufficient to consider two contractor types, those with shallow pockets (type $\mathrm{L}$ ) and those with deep pockets (type $\mathrm{H}$ ). Let $j_{\mathrm{L}}<j_{\mathrm{H}}$ denote the wealths of each type, and let there be $q_{\mathrm{L}}$ contractors of type $\mathrm{L}$ and $q_{\mathrm{H}}$ of type $\mathrm{H}$.

For $\mathrm{i}=\mathrm{L}$ or $\mathrm{H}$, define

$\mathrm{B}_{\mathrm{i}}(k)=$ the net benefits to a contractor of wealth $j_{\mathrm{i}}$ of purchasing from a polluter with capital intensity $k$, as defined in equation (6).

$\mathrm{AC}_{\mathrm{i}}(k)=$ the minimized average costs of a polluter with capital intensity $k$ who sells only to contractors of type $i$.

$$
\begin{aligned}
& \mathrm{U}_{\mathrm{i}}(k)=\mathrm{B}_{\mathrm{i}}(k)-\mathrm{AC}_{\mathrm{i}}(k) ; \text { and } \\
& k_{\mathrm{i}}=\underset{k}{\operatorname{argmax}} \mathrm{U}_{\mathrm{i}}(k)
\end{aligned}
$$


Here the $k_{\mathrm{i}}$ 's are analogous to $\hat{\mathrm{k}}(j)$ defined in equation (8) above. They represent the capital intensity chosen by a polluter dedicated to a single type. Recall from section 4.1 . that $j+\hat{\mathrm{k}}^{*}<\mathrm{L}$ is necessary for a polluter to choose $k(j)<\hat{\mathrm{k}}^{*}$. Therefore, assume $j_{\mathrm{i}}+\hat{\mathrm{k}}^{*}<\mathrm{L}$ for at least one type of contractor. Since $j_{\mathrm{L}}<j_{\mathrm{H}}$, this ensures that the wealthier contractors prefer to purchase from a more capital intensive polluter:

$$
k_{\mathrm{L}}<k_{\mathrm{H}}
$$

When there are constant returns to scale, there are no gains to pooling. Instead, the two types prefer to separate and transact with polluters dedicated to own their types. Less wealthy type L contractors - since they externalize a larger fraction of residual damages - will be served by a relatively undercapitalized polluter, and wealthier type $\mathbf{H}$ contractors by a more capital-intensive polluter. In this case, since separation does not induce production inefficiencies, the argument of section 4.1. applies, and either form of extended liability is more efficient than polluter-only liability.

By contrast, suppose production exhibits sufficient economies of scale so that production costs always decrease as a polluter transacts with more contractors. Thus, all else equal, productive efficiency is maximized when the two types of contractors "pool" and purchase from a common polluter.

When will pooling occur? If pooling occurs with a single type of polluter, that polluter's capital intensity will maximize the total pooled surplus. Thus define

$$
\begin{aligned}
& k_{\mathrm{LH}}=\underset{k}{\operatorname{argmax}} \sum_{\mathrm{i}} q_{i} B_{i}(k)-\mathrm{Q} \cdot \mathrm{AC}(k) \text { where } \mathrm{Q}=\left(q_{\mathrm{L}}+q_{\mathrm{H}}\right) ; \text { and } \\
& \mathrm{AC}_{\mathrm{LH}}=\mathrm{AC}\left(k_{\mathrm{LH}} \mid \mathrm{Q}\right)
\end{aligned}
$$

Here $\mathrm{AC}(k \mid \mathrm{Q})$ is the minimum average cost of a polluter who serves the entire market (Q) and has capital intensity $k$.

Since contractors differ in their demand for polluter capital intensity, evaluating the first-order conditions of problem (15) shows that $k_{\mathrm{L}}<k_{\mathrm{LH}}<k_{\mathrm{H}}$. Thus, pooling implies a polluter capital intensity that is most-preferred by neither contractor $\left(k_{\mathrm{LH}}\right.$ does not maximize either $\mathrm{U}_{\mathrm{L}}$ or $\left.\mathrm{U}_{\mathrm{H}}\right)$. Pooling therefore requires a set of prices $p_{\mathrm{i}}$, and sufficient economies of scale to ensure that

$$
\begin{aligned}
& \mathrm{U}_{\mathrm{i}}\left(k_{\mathrm{i}}\right) \leq \mathrm{B}_{\mathrm{i}}\left(k_{\mathrm{LH}}\right)-p_{\mathrm{i}}, \mathrm{i}=\{\mathrm{L}, \mathrm{H}\}, \text { and } \\
& \sum_{\mathrm{i}} q_{\mathrm{i}} p_{\mathrm{i}} \geq q_{t} \mathrm{AC}_{\mathrm{LH}}
\end{aligned}
$$

Condition (16) says that for pooling to occur, there must be a pair of prices $\left\{p_{\mathrm{L}}, p_{\mathrm{H}}\right\}$ such that at those prices, each type of contractor prefers pooling with a common polluter over separating and transacting with dedicated polluters. ${ }^{9}$ Condition (17) requires that these prices $\left\{p_{\mathrm{L}}, p_{\mathrm{H}}\right\}$ yield revenue adequate to cover production costs.

9 These non-uniform prices may reflect tied insurance or side payments as well as explicit discounts based on contractors' types. 
Figure 1 (a)

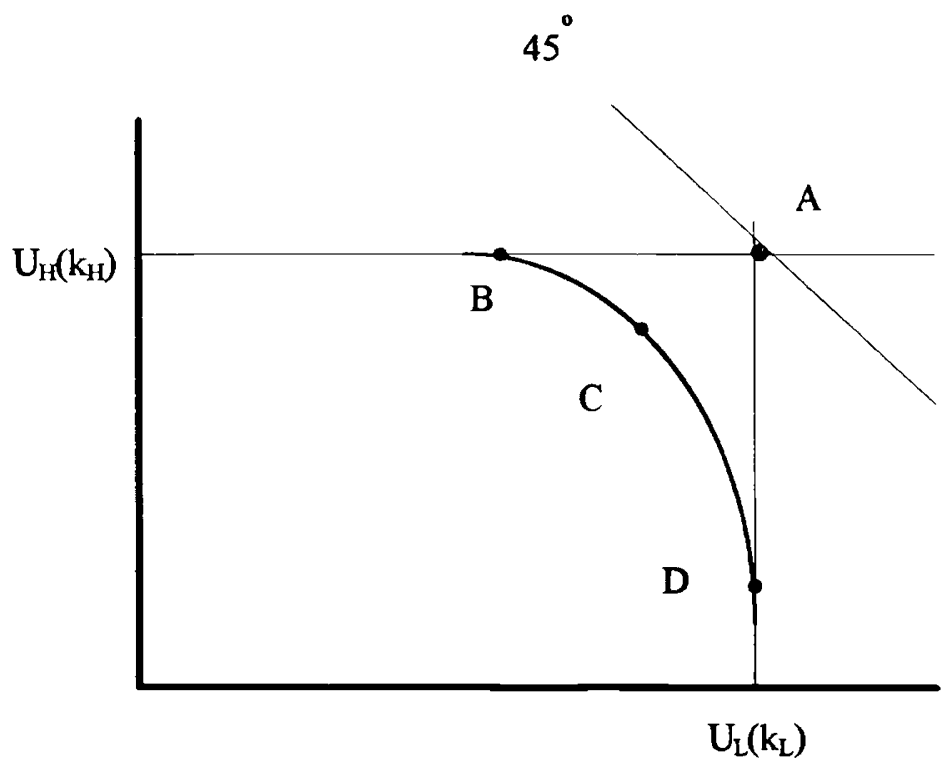

Figure 1 (b)

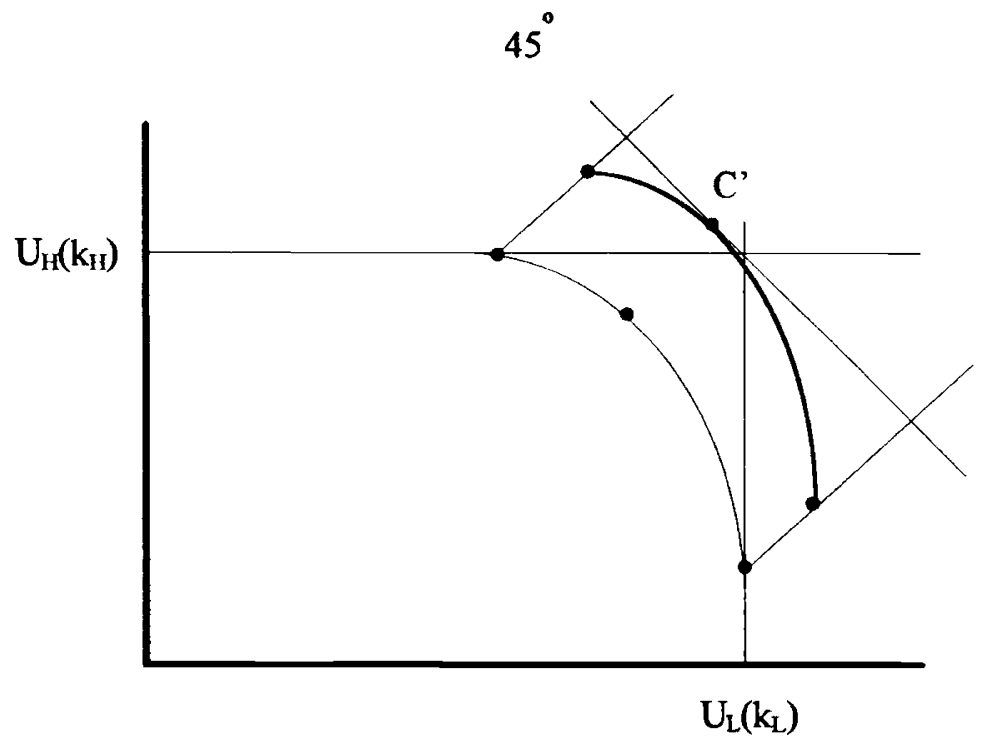


Figure 1 illustrates the choice of dedicated versus common production. Figure 1 (a), illustrates the utility to types $\mathrm{H}$ and $\mathrm{L}$ when production exhibits constant returns to scale. The locus BCD represents utility when production is pooled. Points $\mathrm{B}$ and $\mathrm{D}$ represent the utilities given pooled production at $k_{\mathrm{H}}$ and $k_{\mathrm{L}}$, respectively. Since $k_{\mathrm{L}} \neq k_{\mathrm{H}}$,

$$
\mathrm{U}_{\mathrm{L}}\left(k_{\mathrm{H}}\right)<\mathrm{U}_{\mathrm{L}}\left(k_{\mathrm{L}}\right) \text { and } \mathrm{U}_{\mathrm{H}}\left(k_{\mathrm{L}}\right)<\mathrm{U}_{\mathrm{H}}\left(k_{\mathrm{H}}\right) \text {. }
$$

Point $\mathrm{C}$ denotes the maximum joint utility obtainable from pooling with a polluter with capital intensity $k_{\mathrm{LH}}$. Because there are no economies of scale, joint utility is maximized, not at $\mathrm{C}$, but at the joint utility given separation, $\mathrm{A}=\left\{\mathrm{U}_{\mathrm{H}}\left(k_{\mathrm{H}}\right), \mathrm{U}_{\mathrm{L}}\left(k_{\mathrm{L}}\right)\right\}$.

Figure 1 (b) shows how the utility possibilities available from pooling increase with economies of scale. For example, suppose scale economies are sufficient to shift the pooled utility locus from $\mathrm{BCD}$ to $\mathrm{B}^{\prime} \mathrm{C}^{\prime} \mathrm{D}^{\prime}$. Since $\mathrm{C}^{\prime}$ lies on the $45^{\circ}$ line through $\mathrm{A}$, it yields the same combined utility as separated production. As suggested by the tangency, the utility possibility locus $\mathrm{B}^{\prime} \mathrm{C}^{\prime} \mathrm{D}^{\prime}$ results from the minimum level of scale economies needed to sustain a pooling equilibrium. Note that while the utility of type $\mathrm{L}$ contractors is strictly lower at the pooled equilibrium $\mathrm{C}^{\prime}$ than at $\mathrm{A}$, the benefits to type $\mathrm{H}$ contractors of pooling offset this loss. This implies the existence of a pair of prices $p_{i}$ that will support pooling with a polluter of capital intensity $k_{\mathrm{LH}}$. Of course, larger scale economies than depicted will create a strict preference for common, pooled production. Similarly, if transaction prices cannot be conditioned on contractors' types - for insurance, due to antitrust prohibitions or arbitrage possibilities - then larger scale economies are required to support pooling. For example, if prices are constrained to be uniform, then a pooling equilibrium requires utility possibilities that lie stricktly above and to the right of point $\mathrm{A}$.

\section{Market equilibrium with the joint and several rule}

Proportional liability limits an individual contractor's liability to its proportional share of residual damages, so an individual contractor's expected liability is not affected by the wealth of other contractors who transact with the same polluter. Under joint and several liability, however, individual contractors can be held liable for the full amount of damages avoided by the polluter and less wealthy contractors though insolvency. The prospect of subsidizing shallow pocketed contractors' proportional shares of damages implies an additional cost of pooling to wealthier contractors that is not present under proportional liability.

Indeed, the benefit to a type $\mathrm{H}$ contractor of pooling is strictly lower under joint and several than under proportional liability. And all else equal, the cost of pooling to type $\mathrm{H}$ contractors increases, as the wealth of the type L's $\left(j_{L}\right)$ falls. ${ }^{10}$ As a result, compared to proportional liability, strictly larger returns to scale are needed to support pooling under the joint and several rule.

${ }^{10}$ Consider a loss $b \mathrm{~L}$ which, under proportional liability, would bankrupt the polluter and the type $\mathrm{L}$ contractors, but not the type $\mathrm{H}$ contractors $\left(j_{\mathrm{L}}+k<b \mathrm{~L}<j_{\mathrm{H}}+k\right)$. Under the proportional rule, an $\mathrm{H}$-type contractor's liability is $b \mathrm{~L}-k<j_{\mathrm{H}}$, reflecting the fact that its liability is limited to a $1 / \mathrm{Q}$ share of damages that exceed the polluter's capital value. However, because the type- $L$ contractors are insolvent, they avoid paying their full share of residual liability, leaving a total shortfall equal to $q_{\mathrm{L}}\left[b \mathrm{~L}-\left(k+j_{\mathrm{L}}\right)\right]$. Therefore, under joint and several liability, the type $\mathrm{H}$ contractors' benefits $\mathrm{B}_{\mathrm{H}}(k)$ of transacting are obtained by discounting the benefits under proportional liability (equation (6)) by the fraction of the type L's proportional share of liability that would otherwise be externalized. 
Figure 2

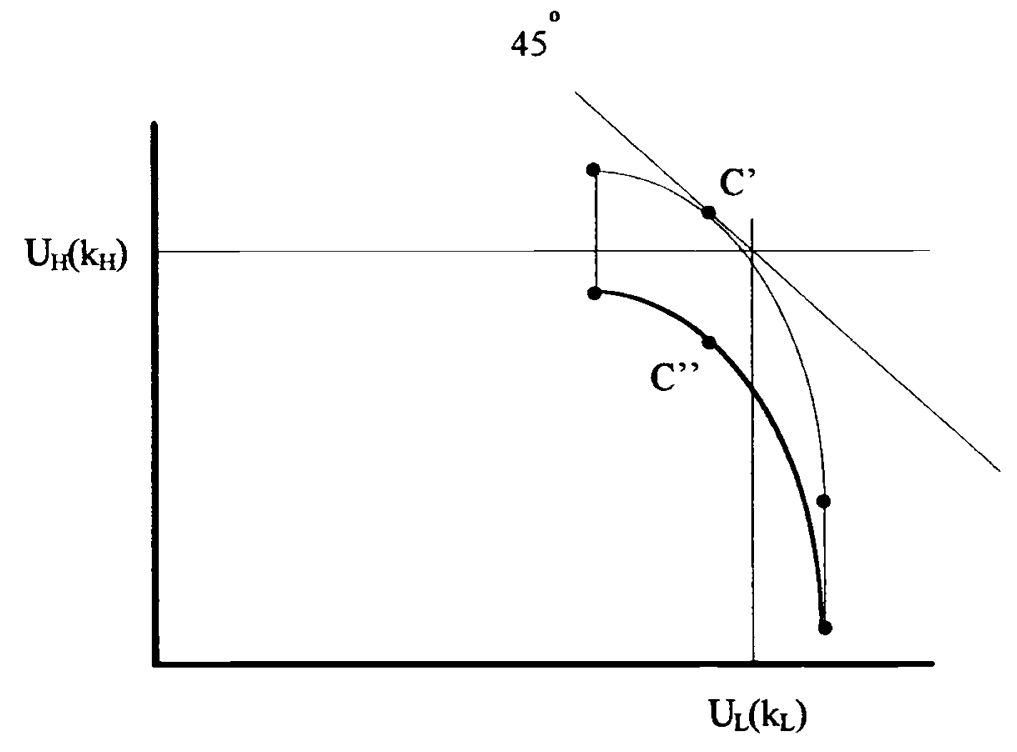

This is illustrated in Figure 2. Recall that under the joint and several rule, a type $\mathrm{H}$ contractor's liability is not capped at its proportional share of the polluter's residual liability. Therefore, given pooling, the joint and several rule forces type $\mathrm{H}$ contractors to internalize more damages than they would under proportional liability. As a result, the maximum combined utility under joint and several $\left(\mathrm{C}^{\prime \prime}\right)$ is strictly less than under proportional liability $\left(\mathrm{C}^{\prime}\right.$ ). Indeed, in this example, joint and several liability does not support pooling, since the combined utility at $\mathrm{C}^{\prime \prime}$ is strictly less than at $\mathrm{A}$ (the utilities available from separating). Of course as scale economies increase, so too do the benefits of pooling.

\subsection{The optimal liability rule}

The analysis above suggests a tradeoff in the choice of rule. All else equal, extending liability increases efficiency by increasing the internalization of costs (joint and several liability leading to the greatest overall cost internalization). However, as shown above, extending liability can reduce production efficiency when it leads to a separating equilibrium. We will now show that in equilibrium, overall welfare may not be increased by the extension of liability, and that joint and several liability need not lead to greater cost intenalization than proportional liability.

\section{Proportional versus polluter-only liability}

We first compare welfare under the proportional liability rule to that under the polluteronly rule. As before, we assume that it is feasible to condition transaction prices on contractor wealth types. 
PROPOSITION 2: Extended, proportional liability increases welfare, relative to polluter-only liability, irrespective of whether or not the extended rule results in lost scale economies.

Proof: Let $\mathrm{W}^{\circ}(\cdot)$ denote welfare under the polluter-only rule and $\mathrm{W}^{\mathrm{p}}(\cdot)$ welfare under the proportional rule. When both rules support pooling, $\mathrm{W}^{\mathrm{p}}(\cdot) \geq \mathrm{W}^{\circ}(\cdot)$. This follows since $k_{\mathrm{LH}} \geq \hat{\mathrm{k}}$ and $\hat{\mathrm{s}}\left(k_{\mathrm{LH}}\right) \geq \hat{\mathrm{s}}(\hat{\mathrm{k}})$, with equality only when $\hat{\mathrm{k}}=\mathrm{k}^{*} \geq \mathrm{L}$.

Even when separation occurs under the proportional rule, however, $\mathrm{W}^{\mathrm{p}}(\cdot)>\mathrm{W}^{\circ}(\cdot)$. This follows since transaction prices can be conditioned on contractor types. That is, if separation occurs,

$$
q_{\mathrm{H}} \mathrm{U}_{\mathrm{H}}+q_{\mathrm{L}} \mathrm{U}_{\mathrm{L}}>q_{\mathrm{L}} \mathrm{B}_{\mathrm{L}}\left(k_{L H}\right)+q_{H} B_{H}\left(k_{\mathrm{LH}}\right)-\mathrm{QAC}_{\mathrm{LH}}\left(k_{\mathrm{LH}} \mid \mathrm{Q}\right),
$$

where $\mathrm{U}_{\mathrm{H}}$ and $\mathrm{U}_{\mathrm{L}}$ denote the representative contractors utilities from separating, as defined in equation (13). By definition (equation (15)), $k_{\mathrm{LH}}$ maximizes the right-hand side of (19), so (19) holds with $k_{\mathrm{L}}$ replacing $k_{\mathrm{LH}}$.

Therefore, rearranging and using the definitions of $\mathrm{U}_{\mathrm{H}}$ and $\mathrm{U}_{\mathrm{L}}$,

$$
q_{\mathrm{H}}\left[\mathrm{B}_{\mathrm{H}}\left(k_{\mathrm{H}}\right)-\mathrm{B}_{\mathrm{H}}\left(k_{\mathrm{L}}\right)\right]>\left[q_{\mathrm{H}} \mathrm{AC}_{\mathrm{H}}+q_{\mathrm{L}} \mathrm{AC}_{\mathrm{L}}\right]-\mathrm{QAC}\left(k_{\mathrm{L}} \mid \mathrm{Q}\right)=B E S,
$$

where the $\mathrm{AC}_{\mathrm{i}}$ are defined as in equation (13), and $\mathrm{AC}\left(k_{\mathrm{L}} \mathrm{Q}\right)$ is the per contractor cost of pooling at $k_{\mathrm{L}}$. Inequality (20) says that the benefits of scale economies due to pooling $(B E S)$ are less than the benefits to type- $\mathrm{H}$ firms of purchasing from a polluter with capital intensity $k_{\mathrm{H}}$ rather than $k_{\mathrm{L}}$. But since $k_{\mathrm{L}}<\hat{\mathrm{k}}^{*}$, the $\mathrm{H}$-type firms internalize no more than the social benefits of production at $k_{\mathrm{H}}$ rather than $k_{\mathrm{L}}$. Therefore, the social benefits of separation rather than pooling at $k_{\mathrm{L}}$ must exceed the social costs, the value of $B E S$. However, pooling at $k_{\mathrm{L}}$ - while not the first-best pooling situation - is more efficient than polluter-only liability, since $\hat{\mathrm{k}}<k_{\mathrm{L}}$ and $\hat{\mathrm{s}}(\hat{\mathrm{k}})<\hat{\mathrm{s}}\left(k_{\mathrm{L}}\right)$. Therefore, $\mathrm{W}^{\mathrm{p}}(\cdot)>\mathrm{W}^{\circ}(\cdot)$ when separation occurs under the proportional rule.

To understand this result, recall that if production exhibits constant returns to scale, then extended liability leads to more efficient polluter safety and capital choices, since each type of contractor can be best served by its most preferred type of polluter. Now suppose there are increasing returns to scale or other economies (e.g., scope) that imply productive efficiency is maximized through pooling. Since production costs fall as output expands, polluter-only liability induces pooling. Clearly, when proportional liability also supports pooling, it is preferred to polluter-only liability: Both rules capture scale economies, but proportional liability leads polluters to strictly more efficient capital and safety investments than those induced by the polluter-only rule (i.e., $k_{\mathrm{LH}}>\hat{\mathrm{k}}$ and $\left.\hat{\mathrm{s}}\left(k_{\mathrm{H}}\right)>\hat{\mathrm{s}}(\hat{\mathrm{k}})\right)$. When proportional liability leads to a separating equilibrium, however, there is an apparent tradeoff between the social benefits of increased safety and capital versus the benefits of scale economies that arise only with pooled production under the polluter-only rule. 
In other words, the central question addressed by the proposition is: When extending liability causes contractors to seek dedicated polluters, are the social benefits of enhanced safety and capital incentives greater than the value of lost scale economies? As shown in the proof, the answer is yes. In equilibrium contractors compare the benefits of capturing scale economies through pooling against the safety benefits of separation. As long as transaction prices can be conditioned on the contractors' types, when separation occurs, it must yield greater combined surplus than does pooled production. Specifically, note that both contractors must prefer to separate rather than pool at $k_{\mathrm{L}}$ (since they prefer separation to pooling at $k_{\mathrm{LH}}$ ). If there is pooling at $k_{\mathrm{L}}$, the type $\mathrm{H}$ contractors capture the full benefits of separation: they transact with a polluter who invests $k_{\mathrm{H}}$ rather than $k_{\mathrm{L}}$. The cost of separation lost returns to scale - must therefore be less than the safety benefits to type H's from separating, which, in turn, cannot exceed the social benefits. Therefore, when separation occurs under proportional liability, the resulting equilibrium is still more efficient than the pooling equilibrium that arises under polluter-only liability.

\section{Joint and several versus proportional and polluter-only liability}

We now bring joint and several liability into the welfare comparison.

PROPOSITION 3: (1) When economies of scale are large, pooling arises under both forms of extended liability. If so, joint and several leads to greater welfare than proportional liability. (2) When economies of scale are small, neither rule supports pooling. In this case, welfare is the same under both forms of extended liability, and either is more efficient than polluter-only liability. (3) Intermediate scale benefits can lead to pooling under the proportional rule but separation under the joint and several rule. When this occurs, both proportional and polluter-only liability can imply greater welfare than joint and several.

Proof: (1) follows since economies of scale are captured under both rules and, because $\mathrm{B}_{\mathrm{H}}(k)$ is smaller under joint and several, $k_{\mathrm{LH}}$ and $\hat{\mathrm{s}}\left(k_{\mathrm{LH}}\right)$ are larger. (2) follows since each form of extended liability implies the same equilibrium $\left(\left\{k_{\mathrm{H}}, k_{\mathrm{L}}\right\}\right.$ and $\left.\left\{\hat{\mathbf{s}}\left(k_{\mathrm{H}}\right), \hat{\mathbf{s}}\left(k_{\mathrm{L}}\right)\right\}\right)$, and, as shown by Proposition 1, proportional is more efficient than polluter-only.

We prove (3) with an example. Assume $j_{\mathrm{H}}=2 \mathrm{~L}$ and $j_{\mathrm{L}} \approx 0$. Then if joint and several induces separation, the two polluters make per-unit capital investments $k_{\mathrm{H}}=\hat{\mathrm{k}}^{*}, k_{\mathrm{L}} \approx \hat{\mathrm{k}}$, while if pooling occurs, $k_{\mathrm{LH}}=\hat{\mathrm{k}}^{*}$ (since the H-type contractor's are sufficiently wealthy to internalize all residual polluter and L-type liabilities).

Suppose separation occurs. Then :

$$
B E S+\hat{\mathrm{s}}(\hat{\mathrm{k}})-q_{\mathrm{L}} w\left(\hat{\mathrm{k}}^{*}-\hat{\mathrm{k}}\right)<q_{\mathrm{L}}\left[\int_{0}^{1} b r\left(b, s^{*}\right) d b-\int_{0}^{1} b r(b, \hat{s}(\hat{k})) d b\right] .
$$

The left-hand side of (21) represents the net private benefits of pooling: the scale economy benefits $B E S$, a savings due to the elimination of a second polluter's safety investment, net of the cost of increased polluter capital. The private cost of pooling is that type $\mathrm{H}$ contractors must internalize the type-L's share of residual damages, which would otherwise be externalized under either proportional or polluter-only liability. 
The separating equilibrium under joint and several is less efficient than the pooled equilibrium given polluter-only liability when

$$
B E S+\hat{\mathrm{s}}(\hat{\mathbf{k}})>q_{\mathrm{H}}\left[\int_{0}^{1} b r\left(b, s^{*}\right) d b-\int_{0}^{1} b r(b, \hat{s}(\hat{k})) d b\right]+q_{\mathrm{H}} w\left(\hat{\mathrm{k}}^{*}-\hat{\mathbf{k}}\right),
$$

or, if the net productive benefits of pooling exceed the incremental social cost of having type $\mathrm{H}$ polluters being served by a polluter making investments $\{\hat{\mathbf{k}}, \hat{\mathbf{s}}(\hat{\mathbf{k}})\}$ instead of $\left\{\hat{\mathbf{k}}^{*}, \mathrm{~s}^{*}\right\}$. It is easy to find parameters to satisfy (21) and (22) simultaneously. For example, suppose $q_{\mathrm{H}}=q_{\mathrm{L}}$. Then the two conditions are identical, except that the term $-q_{\mathrm{H}} w\left(\hat{\mathrm{k}}^{*}-\hat{\mathrm{k}}\right)$ appears on different sides of the inequality. Thus, when joint and several liability leads to separation (and proportional leads to pooling), polluter-only liability can be more efficient than joint and several. (Since $\mathrm{W}^{\mathrm{r}}(\cdot)>\mathrm{W}^{\mathrm{P}}(\cdot)$, welfare under joint and several will also be less than under proportional liability.)

Result (1), when economies of scale are large enough to support pooling under both extended rules, is intuitive. The joint and several rule dominates both proportional and polluter-only liability by forcing greater cost internalization (since the $\mathrm{H}$-type firms' liability is not capped at its proportional share of the residual liability). The joint and several rule, by exposing wealthier contractors to greater liability, leads to higher polluter capital and safety investments.

When economies are so small that neither proportional nor joint and several liability supports pooling, either form of extended liability implies the same equilibrium, and hence the same level of welfare. Recall that the joint and several rule increases wealthier contractors' expected liabilities only when they are liable for a share of residual danages left unfunded by less wealthy contractors. If separation occurs, wealthier contractors, having no relationship with less wealthy contractors, do not bear any additional costs. That is, type $\mathrm{H}$ contractors are liable for their share of residual liabilities under either rule, whether or not separation occurs. As a result, polluters make identical investments to those made under the proportional rule $\left(k_{\mathrm{L}}\right.$ and $\left.k_{\mathrm{H}}\right)$.

When economies of scale are larger, but not enough to support pooling under joint and several, welfare may actually be lower under the joint and several rule than under the polluter-only rule. The incentives of jointly and severally liable type $\mathrm{H}$ firms, in contrast to the incentives of proportionally liable firms, do not ensure that an efficient pooling equilibrium will always be induced. The reason is that one of the social benefits of pooling under joint and several - the fuller internalization of type L's proportional shares of residual damages is in fact a cost to type H's, rather than a benefit.

\section{Conclusion}

This paper has analyzed the effect of extending liability from "polluters" - whose actions directly influence risks - to "contractors" who contribute to risk only through their use of a polluter's product or service. Extended liability is considered in two forms, proportional and joint and several. The analysis features a market in which transactions are endogenous to the liability rule. As a result, contractors' liability for polluters' externalized 
damages leads different contractor types (distinguished by wealth) to seek polluters of different capitalization and safety. And when liability is joint and several, wealthy contractors wish to avoid bearing the liability shares of less wealthy contractors. In this case, contractors may avoid a given polluter simply because less wealthy contractors purchase from it. For these types of reasons, extended liability can distort a market's otherwise efficient patterns of vertical or horizontal integration. The potential benefit of extended liability is that it allows for greater cost internalization and, by inference, more efficient polluter capital and safety investments. However, this benefit must be balanced against potential lost production efficiencies.

The primary welfare result is that proportional liability dominates polluter-only liability as long as polluter prices can be conditioned on contractors' wealth types. This is true even if the extended, proportional rule leads to a separating equilibrium in which production economies are lost. When contractor-specific prices are not possible, however, or when liability is joint and several, the superiority of extended liability is not assured. In particular, uniform pricing can result in separating equilibria in which thinly capitalized contractors prefer to be served by similarly shallow pocketed waste disposers. Similarly, joint and several liability can lead to inefficient market structures when deep pocketed contractors forsake productive efficiencies (e.g., returns to scale or scope) to avoid subsidizing shallow-pocketed contractors' proportional shares of liability. In general, though, as returns to scale increase, efficient market structures (and thereby, strict improvements over polluter-only liability) emerge in equilibrium, even under joint and several liability.

Although these results are suggestive, they are not conclusive. First, we have assumed that it is costless for contractors to observe (or infer) the capitalization of polluters and other contractors with whom the polluter transacts. We believe it reasonable to assume that polluters' wealths are observable to a given contractor at low cost. However, it may be more difficult for one contractor to monitor the wealth of other contractors. If so, then our results for proportional liability will be unchanged, but our analysis overstates the welfare benefits of joint and several liability. This follows since we assume that, under joint and several liability, contractors can accurately condition demand on the degree to which they subsidize (or are subsidized by) other contractors' shares of residual liabilities. In particular, when large transaction costs inhibit contractors from accurately conditioning demand on the solvency of other contractors, our results are likely to understate the loss of productive efficiency implied by joint and several liability.

Second, while we permit economies of scale or scope in production, we have assumed that average costs continue to be U-shaped. As a result, our analysis uses the possibility of entry to justify the assumption of competitive markets. When economies of scale are large, however, the assumption of competitive markets may no longer be tenable. Although results from non-joint liability models do carry over to monopoly markets (see Boyd [1995]), whether our joint liability results will do so is still an open question. However, these and other remaining questions must await future research. 


\section{REFERENCES}

BOYD, J., "Risk, Liability, and Monopoly", International Journal of the Economics of Business, 1, 1994, pp.387-403.

INGBERMAN, D., "Triggers and Priority: An Integrated Model of the Effects of Bankruptcy on Overinvestment and Underinvestment", Washington University Law Quarterly, 72, 1994, pp. 1341-1372.

KORNHAUSER, L., "An Economic Analysis of the Choice Between Enterprise and Personal Liability for Accident", California Law Review, 70, 1982, pp.1345-1385.

---- and REVESZ, R., "Apportioning Damages Among Potentially Insolvent Actors", Journal of Legal Studies, 19, 1990, pp. 617-51.

RINGLEB, A. and WIGGINS, S., "Liability and Large-Scale, Long-Term Hazards", Journal of Political Economy, 98, 1990, pp. 574-95.

SKOGH, G., "Insurance and the Institutional Economics of Financial Intermediation", The Geneva Papers on Risk and Insurance, 16, 1991, pp. 59-72.

SYKES, A., "The Economics of Vicarious Liability", Yale Law Journal, 93, 1984, pp. 1231-1280.

TIETENBERG, T., "Indivisible Toxic Torts: The Economics of Joint and Several Liability", Land Economics, 65, 1989, pp. 305-19.

WIGGINS, S. and RINGLEB, A., "Adverse Selection and Long-Term Hazards: The Choice Between Contract and Mandatory Liability Rules", Journal of Legal Studies, 21, 1992, pp. 189-216. 


\section{Appendix}

Proof of Proposition 1: Recall that average costs are U-shaped in $q$. First consider the first best. Let $P(Q)$ denote the (inverse) demand curve for polluters' output, which we take to represent social benefits. The welfare maximum $\left(\mathrm{s}^{*}, \mathrm{q}^{*}, \mathrm{k}^{*}, \mathrm{n}^{*}\right)$ describes the optimal safety, output, and capital choices of each polluter, and the number of polluters, where $\mathrm{Q}^{*}=\mathrm{n}^{*} \mathrm{q}^{*}$. The first best solves:

$$
\max _{q, s, k, n} \mathrm{~W}(q, s, k, n)=\int_{0}^{n q} P(\mathrm{z}) d z-n C(q, k)-n s-n q \mathrm{~L} \int_{0}^{1} b \cdot r(b, s) d b .
$$

$$
\frac{d \mathrm{~W}}{d q}=n\left(P(n q)-C^{\prime}(q, k)-\mathrm{L} \int_{0}^{1} b \cdot r(b, s) d b\right)=0
$$

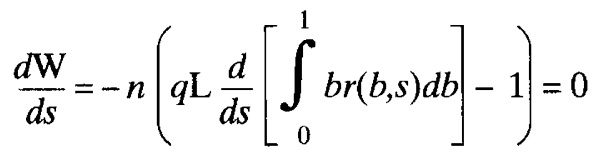

$$
\frac{d \mathrm{~W}}{d k}=-n\left(\frac{d c(q ; k)}{d k}-q w\right)=0
$$

$$
\frac{d \mathrm{~W}}{d n}=q \mathrm{P}(n q)-\mathrm{C}(q, k)-s-q \mathrm{~L} \int_{0}^{1} b \cdot r(b, s) d b=0
$$

where $\mathrm{C}(q ; k)=\mathrm{c}(q ; k)+q w k$ is used in equation (26).

Now consider polluter-only liability. Given its date 1 choice of $k \leqslant \mathrm{~L}$, in market equilibrium at date 2 the polluter solves

$$
\min _{q, s} \operatorname{AC}(q, s, k ; k)=\frac{C(q, k)+s}{q}+\left(\mathrm{L} \int_{0}^{k / L} b \cdot r(b, s) d b+k \int_{k / \mathrm{L}}^{1} r(b, s) d b\right)
$$

Under the assumptions made, for any $k \leqslant \mathrm{~L}$, first order conditions are necessary and sufficient to define the solution to this problem $\{\hat{\mathrm{s}}(k), \hat{\mathrm{q}}(k)\}$.

$$
\frac{d \mathrm{AC}}{d q}=\frac{\mathrm{C}^{\prime}(q, k)}{q}-\frac{\mathrm{C}(q, k)+s}{q^{2}}=0
$$




$$
\frac{d \mathrm{AC}}{d s}=\frac{1}{q}+\frac{d}{d s}\left(\mathrm{~L} \int_{0}^{k / \mathrm{L}} b \cdot r(b, s) d b+k \int_{k / \mathrm{L}}^{1} r(b, s) d b\right)=0
$$

Denote the polluter's choices as $\hat{\mathrm{s}}(k)$ and $\hat{\mathrm{q}}(k)$. For $k>\mathrm{L}$, the first-order conditions for $s$ and $q$ are the same as for the first-best. For $k \leqslant \mathrm{~L}$, standard techniques show that $\hat{\mathrm{s}}(k)$ and $\hat{\mathrm{q}}(k)$ increase with $k$. For $k>\mathrm{L}, \hat{\mathrm{s}}(k)=\mathrm{s}^{*}$. Market equilibrium then requires the polluter to solve

$$
\begin{aligned}
\underset{k}{\min } \operatorname{AC}(\hat{\mathrm{q}}(k), \hat{\mathrm{s}}(k) ; k)=\mathrm{AC}(k)= & \frac{\mathrm{C}(\hat{\mathrm{q}}(k), k)+\hat{\mathrm{s}}(k)}{\hat{\mathrm{q}}(k)}+ \\
& \left(\mathrm{L} \int_{0}^{\min \{k / \mathrm{L}, 1\}} b \cdot r(b, \hat{\mathrm{s}}(k)) d b+k \int_{\min \{k / \mathrm{L}, 1\}}^{1} r(b, \hat{\mathrm{s}}(k) d b)\right.
\end{aligned}
$$

Observe that if $\mathrm{k}^{*}>\mathrm{L}$, then $\mathrm{k}^{*}$ solves this problem. Under the assumptions made, and using the envelope theorem, $\hat{k}$ solves:

$$
\frac{d \mathrm{AC}}{d k}=\frac{1}{\hat{\mathrm{q}}(k)}\left(\frac{\partial c(\hat{\mathrm{q}}(k) ; k)}{\partial k}\right)+w+\int_{k / \mathrm{L}}^{1} r(b, \hat{\mathrm{s}}(k)) d b=0
$$

Rearranging yields (note that $\partial c / \partial k<0$ ):

$$
\frac{1}{\hat{\mathrm{q}}(k)}\left(\frac{\partial c(\hat{\mathrm{q}}(k) ; k)}{\partial k}\right)+w+\int_{k / \mathrm{L}}^{1} r(b, \hat{\mathrm{s}}(k)) d b
$$

The integral on the right hand side of (33) equals the probability of bankruptcy. The result follows by comparing (26) and (33).

Extending Liability to Homogenous Contractors. We first define the second-best capital intensity, $\hat{\mathrm{k}}^{*}$. Let

$$
\Pi_{\mathrm{B}}(k) \equiv \beta-\left[\mathrm{L} \int_{0}^{1} b \cdot r(b, \hat{\mathrm{s}}(k)) d b-\left(\int_{0}^{k / \mathrm{L}} b \cdot r(b, \hat{\mathrm{s}}(k)) d b+k \int_{k / \mathrm{L}}^{1} r(b, \hat{\mathrm{s}}(k)) d b\right)\right]
$$

$\Pi_{\mathrm{B}}(k)$ is the social benefit of capital intensity, reflecting the benefits of production to contractors $(\beta)$ and the expected liabilities not internalized by the firm. Then $\hat{\mathrm{k}}^{*}$ solves

$$
\max _{k} \mathrm{~V}(k)=\Pi_{\mathrm{B}}(k)-\mathrm{AC}(\hat{\mathrm{s}}(k) ; k)
$$


where

$$
\begin{aligned}
\operatorname{AC}(\hat{\mathrm{q}}(k), \hat{\mathrm{s}}(k) ; k) \equiv & \frac{\mathrm{C}(\hat{\mathrm{q}}(k), k)+\hat{\mathrm{s}}(k)}{\hat{\mathrm{q}}(k)}+\left(\mathrm{L} \int_{0}^{k / \mathrm{L}} b \cdot r(b, \hat{\mathrm{s}}(k)) d b+k \int_{k / \mathrm{L}}^{1} r(b, \hat{\mathrm{s}}(k)) d b\right) \\
& =\operatorname{ac}(\hat{\mathrm{q}}(k), \hat{\mathrm{s}}(k) ; k)+\left(\mathrm{L} \int_{0}^{k / \mathrm{L}} b \cdot r(b, \hat{\mathrm{s}}(k)) d b+k \int_{k / \mathrm{L}}^{1} r(b, \hat{\mathrm{s}}(k)) d b\right)
\end{aligned}
$$

Here we use $\operatorname{ac}(q, s ; k)=\frac{C(q ; k)+s}{q}$, and $\mathrm{C}(q ; k)=\mathrm{c}(q ; k)+q \cdot w \cdot k$.

Denote the solution to (35) as $\hat{\mathrm{k}}^{*}$. First-order conditions are necessary for a solution, so $\hat{\mathrm{k}}^{*}$ solves

$$
\begin{aligned}
& \frac{d \mathrm{~V}(k)}{d k}=-\frac{d}{d k}\left(\operatorname{ac}(\hat{\mathrm{s}}(k), \hat{\mathrm{q}}(k) ; k)+\int_{0}^{1} b \cdot r(b, \hat{\mathrm{s}}(k))\right)=0, \text { where } \\
& \frac{d}{d k} \mathrm{~L} \int_{0}^{1} b \cdot r(b, \hat{\mathrm{s}}(k))=\mathrm{L} \frac{\partial}{\partial \hat{\mathrm{s}}(k)}\left[\int_{0}^{1} b \cdot r(b, \hat{\mathrm{s}}(k)) d b\right]\left(\frac{\partial \hat{\mathrm{s}}(k)}{\partial k}\right), \text { and } \\
& \frac{d \mathrm{ac}(\hat{\mathrm{s}}(k), \hat{\mathrm{q}}(k) ; k)}{d k}=\left[\frac{\partial \mathrm{ac}(\cdot)}{\partial \hat{\mathrm{s}}(k)} \frac{\partial \hat{\mathrm{s}}(k)}{\partial k}+\frac{\partial \mathrm{ac}(\cdot)}{\partial \hat{\mathrm{q}}(k)} \frac{\partial \hat{\mathrm{q}}(k)}{\partial k}+\frac{1}{\hat{\mathrm{q}}(k)}\left(\frac{\partial \mathrm{c}(\hat{\mathrm{q}}(k) ; k)}{\partial k}\right)+\mathrm{w}\right] .
\end{aligned}
$$

Using equation (29), we note that $\frac{\partial \mathrm{ac}(\cdot)}{\partial q}=$ at $\hat{\mathrm{q}}(\mathrm{k})$. Rearranging (37) yields.

$$
\left(\frac{\partial \hat{\mathrm{s}}(k)}{\partial k}\right)\left(-\frac{\partial \mathrm{ac}(\cdot)}{\partial \hat{\mathrm{s}}(k)}-\mathrm{L} \frac{\partial}{\partial \hat{\mathrm{S}}(k)}\left[\int_{0}^{1} b \cdot r(b, \hat{\mathrm{s}}(k)) d b\right]\right)-\frac{1}{\hat{\mathrm{q}}(k)}\left(\frac{\partial \mathrm{c}(\hat{\mathrm{q}}(k) ; k)}{\partial k}\right)=\mathrm{w}
$$

Observe that the entire left hand side of (39) is positive, since $\partial \mathrm{c}(q ; k) / \partial k<0, \partial \hat{\mathrm{s}}(k) / \partial k>0$, and the term in the brackets is positive at $\hat{\mathrm{s}}(k)$ (by equation (30)).

Comparing (39) to (33) shows that $\hat{k}^{*}>\hat{k}$. That is, compared to joint and several the "induced marginal benefits" of $k$ under polluter-only liability (the right hand sides of (33) and (39)) are smaller, while the "induced marginal costs" (the left hand sides of (33) and (39)) are larger. Thus, the left hand side of (39) reflects the implied safety value of the capital investment, plus the productivity gain, minus the increment to average costs by the change in $\hat{\mathrm{s}}(k)$ induced by the higher $k$, while the right hand side of (39) consists of the opportunity cost of capital, $w$.

Comparing (39) to (26) shows that $\mathrm{k}^{*}<\hat{\mathrm{k}}^{*}$ when $\mathrm{k}^{*}<\mathrm{L}$. This follows since the marginal cost of capital is the same in each case, while the marginal benefits of increased capital under joint and several liability are larger than at the first best. 